\title{
INFLUENCE OF INITIAL OPERATING CONDITIONS ON TECHNOLOGICAL FUNCTION PARAMETERS OF SERVICING SYSTEMS - MACHINES AND DEVICES
}

\author{
Ugljesa Bugaric, Milan Vugdelija, Dusan Petrovic, Dusan Glisic, Zoran Petrovic
}

Original scientific paper In warehousing and production systems, every device or machine re-commissioning after malfunction or at the start of a new shift, leads to their nonstationary operating regime caused by a certain number of residual unprocessed units. In warehouse systems, non-stationary operating regime is common when palletized goods are stored in one (two) shifts while their production runs in two (three) shifts. Such situations influence technological function parameters (TFPs) of production or warehousing systems. On the other hand, non-stationary operating regime of a single device or machine may be modelled as a single server servicing system with a finite waiting room - M/M/1/K. As a result, general analytical integration constants expression was derived based on initial arbitrary system state probability values. Influence of initial non-stationary operating regime and its duration on warehousing system TFPs is evaluated in view of the operating conditions of an existing high bay pallet warehouse.

Keywords: $M / M / 1 / K$; operating cycle; production; transient probabilities; warehousing

Utjecaj početnih radnih uvjeta na parametre tehnološke funkcije sustava opsluživanja - strojeva i uređaja

Izvorni znanstveni članak

U skladišnim i proizvodnim sustavima, svaki novi početak rada uređaja ili stroja poslije otkaza ili na početku nove smjene, dovodi do njihovog nestacionarnog režima rada izazvanog određenim brojem zaostalih neopsluženih jedinica. U skladišnim sustavima nestacionarni režim rada je uobičajena situacija kada je skladištenje paletizirane robe moguće u jednoj ili dvije smjene dok se proizvodnja odvija u dvije ili tri smjene. Opisane situacije utječu na parametre tehnološke funkcije (TFP) skladišnih ili proizvodnih sustava. Nestacionarni režim rada pojedinačnih uređaja ili strojeva može se modelirati kao jednokanalni sustav opsluživanja s ograničenim redom - M/M/1/K. Stoga je opći analitički izraz za integracijske konstante izveden na osnovu proizvoljnih početnih vrijednosti vjerojatnoća stanja sustava. Utjecaj početnog nestacionarnog režima, kao i njegovo trajanje, na TFP skladišnog sustava je kvantificiran uzimajući u obzir radne uvjete u postojećem paletnom visokoregalnom skladištu.

Ključne riječi: $M / M / 1 / K$; radni ciklus; proizvodnja; vemenski zavisne vjerojatnoće; skladištenje

\section{Introduction}

In factories or workshops at the end of each shift or after each malfunction a different random number of parts remain unprocessed in front of each machine or production line. Different random number of parts at the end of each shift depends on several factors such as: final product type, production preparation, part availability etc., while after malfunctions this number depends on the availability of spare parts (inventory) and repair crews, organizational and logistic times as well as the required repair time. This leads to situations where at the start of each operating day i.e. shift or after each malfunction remaining parts have to be processed first. This random number of unprocessed parts causes non-stationary operating regimes of machines and production lines with different technological function parameters (TFPs) than the design ones, influencing the production process.

The same situation happens when production runs in two or three shifts while warehousing of palletized final goods runs only in one or two shifts, or after storage device malfunction. When a storage device (fork lift truck, $\mathrm{S} / \mathrm{R}$ machine) is re-commissioned, existing random number of pallets leads to a non-stationary operating regime. Non-stationary operating regime of a storage device, with altered TFPs, influences the warehousing process - arrival and departure of pallets.

On the other side, operation of a single machine, production line or a storage device (server) may be considered as a servicing system and mostly modelled as a single server servicing system with a finite waiting room $-M / M / 1 / K$ (irreducible homogeneous Markov chain of birth and death type). Generally servicing systems are used to describe time dependent processes where system states $(0,1,2, \ldots, K)$, defined by system state probabilities, depend on the number of its customers (parts, pallets) i.e. units. Change of servicing system state probabilities in time $\left(p_{0}(t), p_{1}(t), \ldots, p_{K}(t)\right)$ is defined by the system of first order differential equations dependent on initial conditions (state).

Due to the ergodic property of the Markov chain, after a certain time period (theoretically when time is ten to infinity), servicing system state probabilities practically become independent from time and initial conditions forming a limiting state probability distribution $\left(p_{0}, p_{1}, \ldots\right.$, $\left.p_{K}\right)$. In other words, servicing system is in equilibrium when its system state probabilities are independent of time and initial state.

This time period in which the servicing system state probabilities depend on time and initial state is in fact a period in which a servicing system (machines, production lines or storage devices) is operating in a non-stationary regime with altered TFPs.

Random number of parts or pallets i.e. units at the start of a shift or after malfunction represent initial conditions - initial state directly influencing the duration of a non-stationary operating regime and servicing system TFPs. This stochastic influence may only be taken into consideration through appropriate finite discrete theoretical or empirical probability distribution. Meaning that influence of arbitrary number of units potentially occurring at the start of a shift or after malfunction may be defined with appropriate probability distribution $\left(\pi_{0}\right.$, $\left.\pi_{1}, \ldots, \pi_{K}\right)$. 
Duration of a non-stationary operating regime where machines, production lines or storage devices are operating with altered (mostly worse) TFPs, for practical applications, may be defined as a moment of time when a relative error between time dependent system state probabilities $-p_{i}(t)$ and limiting system state probabilities $-p_{i}$, is smaller than the required value. The moment when the relative errors for all system state probabilities are lower than the required value (empirical value $1 \%$ ) is the end of a non-stationary operating regime. After such moment, it may be assumed that a servicing system is operating under a stationary operating regime with designed TFPs.

In order to analytically determine TFP values during a non-stationary operating regime as well as its duration, caused by random number of units at the start of a shift or after malfunction, analytical expression for integration constants based on initial state probability distribution $\left(\pi_{0}\right.$, $\left.\pi_{1}, \ldots, \pi_{K}\right)$ needs to be derived. Given that general analytics for system state probabilities of an $M / M / 1 / K$ servicing system is known, this derivation is the main mathematical focus and contribution of the paper.

Impact of such initial non-stationary operating regime, as well as its duration, on warehousing servicing system TFPs is evaluated by using an existing high bay pallet warehouse.

\subsection{Literature survey}

To better understand the topic analysed by this paper, literature survey focuses on a relationship between inventory (warehousing and material handling) and analytical models of servicing systems.

Song and Zipkin [1] analysed inventory control in a fluctuating demand environment. Overall demand was modelled as a Markov modulated Poisson process. Gullu [2] studied base stock policies for production and inventory problems with uncertain production capacity levels. Scheller-Wolf and Tayur [3] developed dual source production and inventory model with Markovian demands and Markovian capacity constraints.

Some later papers also examined inventory models with potential supply disruptions. Erdem and Ozekici [4] considered inventory models with random yield in a random environment. They observed a single item inventory model with randomly altered environment. All model parameters were specified by the state of the environment which is assumed to be a homogeneous continuous time Markov chain. Chen and $\mathrm{Yu}$ [5] investigated quantification value of lead-time information in a single-location inventory system, for optimal warehouse system capacity.

However, more realistic cases of non-stationary regime in the control field have received less attention; therefore it is essential to note that there is a lack of empirical investigations in this area. [6]

Some authors analysed non-stationary demands on inventory control. Iida [7] points out uncertainties in production processes, for instance, unexpected breakdowns of equipment, unplanned maintenance, observed from the point of non-stationary analyses. Strijbosch et al. [6] examined non-stationary demands using simulation methods. Xu [8] analysed single product, multi-period, non-stationary, stochastic inventory problem with capacity commitment from the buyer's perspective. He identified conditions under which miopic ordering policy is an optimal and derived equation for optimal capacity commitment suggesting a model which takes into consideration a multi-product inventory case in which all products share warehouse capacity as the course of future investigations.

Treharne and Sox [9] explored adaptive inventory control for non-stationary demand and partial information. They considered demand process as a nonstationary process in which probability distribution for the demand in each period is determined by the Markov chain state.

Analytical analysis of queuing systems is in most cases restricted to systems in equilibrium. The main reason for this is that a system of linear first order differential equations has to be solved to obtain time dependent state probabilities. Unfortunately, analytical solutions are rare and if they exist, their determination is rather difficult.

Takacs [10] considered time dependence of an $M / M / 1 / K$ queuing system. He derives analytical expression for transition probabilities by solving the socalled Chapman-Kolmogorov equation, employing a eigenvalues technique, based on the initial condition that the system is in an $m^{\text {th }}$ state (there are exactly $m$ customers i.e. units in the queuing system) at the beginning of observation (operation). Morse [11] provides an analytical solution for time dependent system state probabilities of a single server queuing system with maximum $N$ system states, using trigonometric identities. This solution is derived from an initial condition that system is in an $m^{\text {th }}$ state at $t=0$. Both Takacs and Morse expressed the results involving trigonometric functions.

Sharma and Gupta [12] used the Laplace transform to obtain time dependent solution of an $M / M / 1 / K$ queue, expressed in terms of the Chebyshev's polynomials.

Tarabia and El-Baz [13] derive a transient solution for an $M / M / 1 / K$ queue with any arbitrary (integer) number of customers being present in the system initially. Tarabia [14] besides measuring effectiveness such as first and second order moments of queue length, gives a detailed procedure to obtain an expression for time dependent system state probabilities in the case of an empty system at $t=0$ time, based on the Laplace transforms and Chebyshev's polynomials.

\section{System description - warehouse}

Analysed warehouse distribution system of a pharmaceutical company comprises one warehouse designed for acceptance, storage and distribution of final goods. This warehouse has the capacity of 864 pallet places arranged in four aisles with eight pallet racks served with one S/R machine (Demag Destamat 600 - P.1, Fig. 1) equipped with one aisle changing device (Demag Destamat 1516 - P.2, Fig. 1). $1200 \times 800 \mathrm{~mm}$ euro pallet is used for storage, with a maximum safe operating load of $600 \mathrm{~kg}$. [15]

Warehouse distribution system for final goods comprises: a goods acceptance area (area where palletized 
goods arrive from production), high bay warehouse and a goods distribution area.

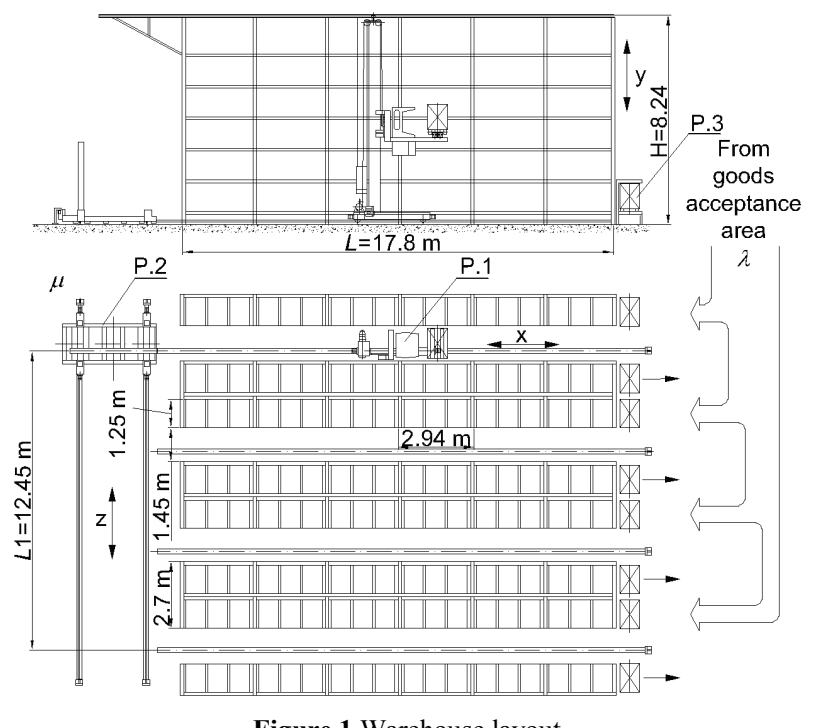

Figure 1 Warehouse layout

Warehouse logistic system is conceptually designed for goods transport by trucks and vans.

Acceptance control of final palletized goods is done in the goods acceptance area. After information system approval and recognition, a unique pallet place address is assigned (address consisting of an aisle number, rack, module and pallet place number) while pallets are subsequently delivered to the high bay warehouse. Fork lifts are used to transport pallets from the production to the goods acceptance area and subsequently from the acceptance area to the rack console acceptance place (P.3, Fig. 1). From this point an S/R machine can pick it up and take it to the position defined by the assigned address. Every acceptance place consists of two pallet places, also used for dimension control. The above-indicated activities comprise the warehouse servicing system analysed below.

High bay warehouse dimensions shown in Fig. 1 are: rack length $L=17,8 \mathrm{~m}$, rack height $H=8,24 \mathrm{~m}$, aisle width $1,45 \mathrm{~m}$ while pallet module dimensions (3 pallet places) are $2940 \times 1350 \mathrm{~mm}$ with a height of $1300 \mathrm{~mm}$.

Warehouse and production are operating in one and two shifts, respectively.

\section{Warehouse system parameters 3.1 Arrival of pallets}

Arrival of palletized final goods from production to the warehouse goods acceptance area is a direct result of the existing group production technology. Production program involves different products differing by production quantity and dynamics, which in return provides a stochastic number of pallets produced in one day. This indicates the existence of a strong stochastic behaviour of arrival flow. According to the research by one of the authors, out coming - servicing flow of such production type may be described by exponential distribution [16]. Out coming - servicing flow from production is simultaneously an arrival flow to the warehouse servicing system. The same conclusion that the arrival flow of pallets to the high bay warehouse may be described by exponential distribution was also reached by
Gudehus [17]. Mean arrival rate $-\lambda$ is defined according to the exponentially distributed arrival flow.

\subsection{S/R machine operating cycle}

In today's design practice, the mean single operating cycle of an S/R machine in one aisle is calculated in line with the FEM regulation (Federation Europeenne de la Manutention - FEM, No. 9.851). Data needed for this calculation include:

- movement in $x$-direction: max. speed $40 \mathrm{~m} / \mathrm{min}$, acceleration $0,4 \mathrm{~m} / \mathrm{s}^{2}$, positioning speed $1,25 \mathrm{~m} / \mathrm{min}$, positioning path $0,2 \mathrm{~m}$, max. path $17,8 \mathrm{~m}$,

- movement in $y$-direction: max. speed $12 \mathrm{~m} / \mathrm{min}$, acceleration $0,4 \mathrm{~m} / \mathrm{s}^{2}$, positioning speed $0,75 \mathrm{~m} / \mathrm{min}$, positioning path: $0,2 \mathrm{~m}$, max. path $8,24 \mathrm{~m}$,

- entrance/exit position of pallets in rack (x/y): 0,0/0,0 m,

-telescoping: extraction/retraction fork speed: 22,3 $\mathrm{m} / \mathrm{min}$, acceleration: $0,6 \mathrm{~m} / \mathrm{s}^{2}$, path: $1,325 \mathrm{~m}$,

- pallet lifting/lowering path in rack: $0,1 \mathrm{~m}$.

$\mathrm{S} / \mathrm{R}$ machine movement, in $x$ and $y$ direction is optimised by using a maximum principle [18, 19]. According to the above data, mean single $\mathrm{S} / \mathrm{R}$ machine operating cycle in one aisle is: $T_{c}^{S / R}=98,47 \mathrm{~s}$.

Considering that one $\mathrm{S} / \mathrm{R}$ machine is operating in four aisles inside the analysed high bay warehouse and that the movement between aisles is aided by an aisle changing device, mean time needed for $\mathrm{S} / \mathrm{R}$ machine transfer from one aisle to the other has to be calculated. This mean time involves: mean time needed for $\mathrm{S} / \mathrm{R}$ machine to leave the aisle and move to the aisle changing device (mean path in $x$-direction: $L / 2$ ), required mean time for an aisle changing device, with $\mathrm{S} / \mathrm{R}$ machine on, aisle to aisle transfer (mean path in $z$-direction: $L_{1} / 2$ ) and time needed for an $\mathrm{S} / \mathrm{R}$ machine to leave the aisle changing device and reach the rack console acceptance place in the new aisle (path in $x$-direction: $L$ ).

Data needed to calculate the mean time for aisle changing device transfer ( $z$-direction) include: maximum speed $40 \mathrm{~m} / \mathrm{min}$, acceleration $0,2 \mathrm{~m} / \mathrm{s}^{2}$, positioning speed $1,25 \mathrm{~m} / \mathrm{min}$, positioning path $0,2 \mathrm{~m}$, mean path $L_{1} / 2=6,225 \mathrm{~m}$, (half of the warehouse width).

Movement of the aisle changing device is optimised by employing the maximum principle. According to the above data, mean time needed for $\mathrm{S} / \mathrm{R}$ machine transfer from one aisle to the other, by means of an aisle changing device, is: $T_{c}^{a c d}=94,90 \mathrm{~s}$.

Empirical data taken from the analysed warehouse indicate that an $\mathrm{S} / \mathrm{R}$ machine on average makes four cycles within one aisle before it is transferred to another aisle [15]. Finally, average operating cycle of an $S / R$ machine with the use of an aisle changing device is $T_{c}=122,2 \mathrm{~s}$, or 2,0367 minutes. Based on this, mean servicing rate $\mu$ of an $\mathrm{S} / \mathrm{R}$ machine is defined as: $\mu=1 / T_{c}=$ $0,008181 / \mathrm{min}$.

\subsection{Servicing time distribution}

$\mathrm{S} / \mathrm{R}$ machine operating cycle duration is a stochastic value, where time distribution depends on operating cycle 
characteristics, warehouse system configuration and pallet storing strategy into racks.

Operation of most material handling devices, such as an $\mathrm{S} / \mathrm{R}$ machine, is based on cycles. Generally, operating cycle of such devices may be divided into: time needed for device movement and additional time needed for individual operating cycle operations. Additional time is mostly a constant value, depending on transport devices characteristics, or an empirically determined value (for example: $\mathrm{S} / \mathrm{R}$ machine positioning, control of functions, device start/stop, etc.).

One of the most important operating cycle characteristics of material handling devices is an operating cycle with minimum duration. This is explained by the fact that the material handling devices operating cycle, including an $\mathrm{S} / \mathrm{R}$ machine, comprises operations that have to be executed in every operating cycle (additional time), regardless of device movement.

Contemporary warehouse systems are supported by control and information systems based on the pallets storage strategy along aisles and racks within a warehouse (e.g. Pareto principle with $\mathrm{ABC}$ analyses for storing pallets along aisles and racks closest to the warehouse entry/exit). This strategy results in more frequent use of individual warehouse zones or pallet places closer to the aisle entry/exit.

In addition, an aisle changing device in a warehouse system influences an $\mathrm{S} / \mathrm{R}$ machine operating cycle time distribution by increasing the stochastic impact.

The above $\mathrm{S} / \mathrm{R}$ machine operating cycle time distribution impacts were quantified based on the examined warehouse, leading to a conclusion that an $S / R$ machine operating cycle time distribution may be described by exponential distribution of the following form: [15]

$$
f(t)=\alpha \cdot \mathrm{e}^{-\alpha \cdot\left(t-t_{0}\right)}, \quad t>=t_{0}>=0
$$

which mean: $E(t)=t_{0}+1 / \alpha$, where $\alpha$ is parameter of exponential distribution.

In this case $\mathrm{S} / \mathrm{R}$ machine operating cycle duration is treated as a random variable $\left(t-t_{0}\right)$, given that the $\mathrm{S} / \mathrm{R}$ machine operating cycle cannot be shorter than a minimum value i.e. $t_{0}$.

\subsection{Warehouse servicing model}

Conclusions of the previous two chapters indicate that servicing of the analysed warehouse may be modelled, under previously defined conditions, with a single server servicing system including a finite waiting room $-M / M / 1 / K$. In a warehouse servicing system, the server will be represented by an $\mathrm{S} / \mathrm{R}$ machine with an aisle changing device while the goods acceptance area will represent a finite waiting room. Servicing in a warehouse servicing system consists of pallet picking from rack console acceptance place and transport by an $\mathrm{S} / \mathrm{R}$ machine to the position defined by the assigned address.

\subsection{Initial conditions for warehouse servicing system operation}

As already mentioned for the analysed system, warehouse and production line operate in one and two shifts, respectively. In view of this, at the start of each operating day of the warehouse goods acceptance area, pallets have already arrived from the production line. Their number is a random variable depending on the product type, production dynamics, production malfunctions etc.

To define the warehouse servicing system variable palette number impact, within the goods acceptance area, authors recorded the number of pallets at the start of each operating day consecutively. Recorded data indicate that the number of pallets was not greater than $20(K=20)$, meaning that this may be assumed as maximum capacity of the servicing system.

Recorded data (Sample) are shown in Fig. 2 histogram, together with adequate theoretical probability distribution i.e. Poisson distribution - $P o(10,488)$.

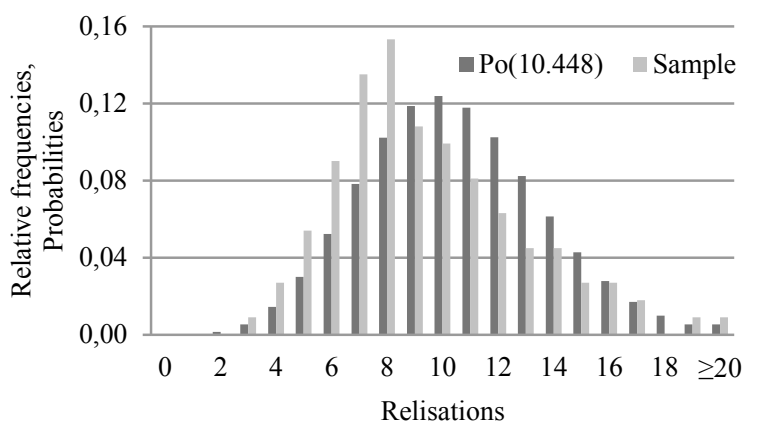

Figure 2 Sample and Poisson distribution

The one sample Kolmogorov-Smirnov test is used to verify whether the sample given in Fig. 2 fits the Poisson distribution with parameter $\lambda_{p}=10,488$, where the $\mathrm{p}$-value of the test is 0,888 and the significance level 0,05 , using the SPSS statistical software [20].

Poisson distribution obtained from the sample:

$\operatorname{Po}\left(\lambda_{p}\right)=\frac{\lambda_{p}}{i !} \cdot e^{-\lambda_{p}} \Rightarrow \pi_{i}, \quad i=0,1,2, \ldots, 20$

will be used to determine the impact of non-stationary operating regime, caused by initial conditions $\left(\pi_{i}\right)$, on the analysed warehouse servicing system TFPs modelled with $M / M / 1 / K$

\section{$4 \quad M / M / 1 / K$ servicing system}

Corresponding system of linear first order differential equations, defining the time dependent state probabilities of the $M / M / 1 / K$ servicing system, is: [21]

$$
\begin{aligned}
& p_{0}^{\prime}(t)=-\lambda \cdot p_{0}(t)+\mu \cdot p_{1}(t) \\
& \quad \vdots \\
& p_{i}^{\prime}(t)=\lambda \cdot p_{i-1}(t)-(\lambda+\mu) \cdot p_{i}(t)+\mu \cdot p_{i+1}(t) ; \quad i=1, \ldots, K-1 \\
& \quad \vdots \\
& p_{K}^{\prime}(t)=\lambda \cdot p_{K-1}(t)-\mu \cdot p_{K}(t)
\end{aligned}
$$


where: $\lambda$ is mean arrival rate, $\mu$ is mean service rate, $p_{i}(t)$ is time dependent probability that the system at the time $t$ will be in the state $i$, and $p_{i}^{\prime}(t)=\mathrm{d} p_{i}(t) / \mathrm{d} t$ is first derivation of the $p_{i}(t)$ per time, $i=0,1, \ldots, K, t \geq 0$.

System (3) may be written in a matrix form as: $P^{\prime}(t)_{(K+1) \times 1}=Q_{(K+1) \times(K+1)} \times P(t)_{(K+1) \times 1}$

where:

$$
Q=\left[\begin{array}{ccccccc}
-\lambda & \mu & 0 & \cdots & 0 & 0 & 0 \\
\lambda & -(\lambda+\mu) & \mu & \cdots & 0 & 0 & 0 \\
\vdots & \vdots & \vdots & \vdots & \vdots & \vdots & \vdots \\
0 & 0 & 0 & \cdots & \lambda & -(\lambda+\mu) & \mu \\
0 & 0 & 0 & \cdots & 0 & \lambda & -\mu
\end{array}\right]
$$

is transition rate matrix [21] while $P^{\prime}(t)=\left[p_{i}^{\prime}(t)\right]$, $P(t)=\left[p_{i}(t)\right]$ are column vectors.

\subsection{Analytical expressions for system state probabilities}

Analytical solution of differential equations system (3) may be found in works by several authors, such as: Takacs [10], Morse [11], Sharma and Gupta [12], Tarabia and El-Baz [13] etc. (chapter 1.1).

Common attribute of such analytical solutions is the fact that they are derived for arbitrary (integer) number of customers $(m)$ being present in the system initially i.e. upon initial condition that system is in the $m$-th state $(0 \leq m \leq K)$ at $t=0$. In such case initial conditions are:

$\pi_{i}=\left\{\begin{array}{ll}1 & i=m \\ 0 & i \neq m\end{array}, \quad i=0,1,2, \ldots, K\right.$.

It is obvious that analytical solutions of system (3), mentioned above, cannot be used for ongoing analysis due to different shape of initial conditions - see expression (2). Therefore, this paper identifies an alternative expression for integration constants in analytical form, on the basis of the common shape of initial conditions.

General analytical solution of system (3), without integration constants expressions, may be written in the following form: [18]

$$
\begin{aligned}
& p_{i}(t)=C_{0} \cdot \rho^{i}+(\sqrt{\rho})^{i-1} \cdot \sum_{k=1}^{K} \frac{C_{k}}{\sin (k \cdot \psi)} . \\
& \cdot\{\sqrt{\rho} \cdot \sin [(i+1) \cdot k \cdot \psi]-\sin (i \cdot k \cdot \psi)\} \cdot \mathrm{e}^{r_{k} \cdot t},
\end{aligned}
$$

where: $i=0,1,2, \ldots, K ; \quad \rho=\lambda / \mu-$ utilisation factor; $\psi=$ $\pi /(K+1) ; r_{0}, r_{k}(k=1,2, \ldots, K)$ eigenvalues of matrix $Q$ (4); $C_{i}$ are integration constants determined based on initial values of system state probabilities $\left(\pi_{i}\right)$.

The next chapter presents an alternative procedure applied to identify integration constants $\left(C_{i}\right)$ in analytical form, based on the common shape of initial conditions.

\subsection{Integration constants}

Determining integration constants, in a classical way, assumes that algebra linear equations system has to be solved. When the number of equations is relatively small it is easy to determine integration constants in analytical form, but when the number of equations is large or given as a general number it is practically impossible to obtain analytical expressions for integration constants by applying the classical method. Therefore, this chapter presents an alternative procedure for determining integration constants in analytical form, based on specific properties of analytical expression for time dependent system state probabilities of the $M / M / 1 / K$ servicing system - expression (5).

Integration constants will be determined for initial values of system state probabilities, i.e. $p_{i}(t=0)=\pi_{i}$ $(i=0,1,2, \ldots, K)$, defined by general finite discrete probability distribution. To determine integration constants of differential equations system (3) only system state probability $p_{0}(t)$ will be derived by using the Laplace transform.

Applying the Laplace transform on system of linear first order differential equations (3) and using some properties of the Laplace transform system (3) may be written as: [21]

$$
\begin{aligned}
& (\lambda+r) \cdot \bar{p}_{0}-\mu \cdot \bar{p}_{1}=\pi_{0} ; \\
& \quad \vdots \\
& -\lambda \cdot \bar{p}_{i-1}+(\lambda+\mu+r) \cdot \bar{p}_{i}-\mu \cdot \bar{p}_{i+1}=\pi_{i} ; i=1,2, \ldots, K-1 \\
& \quad \vdots \\
& -\lambda \cdot \bar{p}_{K-1}+(\mu+r) \cdot \bar{p}_{K}=\pi_{K} ;
\end{aligned}
$$

where Laplace transforms of the system state probabilities and the first derivation of system state probabilities per time are: $\mathscr{L}\left\{p_{i}(t)\right\}=\bar{p}_{i}$ and $\mathscr{L}\left\{p_{i}^{\prime}(t)\right\}=r \cdot \bar{p}_{i}-\pi_{i}$. The above system may be written in the following matrix form:

$$
\left[\begin{array}{ccccccc}
\lambda+r & -\mu & 0 & \cdots & 0 & 0 & 0 \\
-\lambda & \lambda+\mu+r & -\mu & \cdots & 0 & 0 & 0 \\
\vdots & \vdots & \vdots & \vdots & \vdots & \vdots & \vdots \\
0 & 0 & 0 & \cdots & -\lambda & \lambda+\mu+r & -\mu \\
0 & 0 & 0 & \cdots & 0 & -\lambda & \mu+r
\end{array}\right] \cdot\left[\begin{array}{c}
\bar{p}_{0} \\
\bar{p}_{1} \\
\vdots \\
\bar{p}_{K-1} \\
\bar{p}_{K}
\end{array}\right]=\left[\begin{array}{c}
\pi_{0} \\
\pi_{1} \\
\vdots \\
\pi_{K-1} \\
\pi_{K}
\end{array}\right]
$$

The matrix equation (6) indicates that the square matrix is in fact a $[-1 \cdot(Q-r \cdot E)]$ matrix; elements of column vectors are Laplace transform of system state probabilities and initial values of system state probabilities while $E$ is unit matrix.

Laplace transform of system state probability $p_{0}(t)$ may be determined from the above system (6) by using the Cramer's rule: [22]

$\bar{p}_{0}=D_{\bar{p}_{0}} / D_{K+1}$,

where: 
$D_{\bar{p}_{0}}=\left|\begin{array}{ccccccc}\pi_{0} & -\mu & 0 & \cdots & 0 & 0 & 0 \\ \pi_{1} & \lambda+\mu+r & -\mu & \cdots & 0 & 0 & 0 \\ \vdots & \vdots & \vdots & \vdots & \vdots & \vdots & \vdots \\ \pi_{K-1} & 0 & 0 & \cdots & -\lambda & \lambda+\mu+r & -\mu \\ \pi_{K} & 0 & 0 & \cdots & 0 & -\lambda & \mu+r\end{array}\right|$

and $D_{K+1}=\operatorname{det}[-1 \cdot(Q-r \cdot E)]$.

Furthermore, determinant $D_{K+1}$ may be written as:

$D_{K+1}=(\lambda+r) \cdot P_{K}-\lambda \cdot \mu \cdot P_{K-1}$

where $P_{K}$ is a square determinant of dimension $K$, i.e.:

$$
\left|\begin{array}{ccccccc}
\lambda+\mu+r & -\mu & 0 & \cdots & 0 & 0 & 0 \\
-\lambda & \lambda+\mu+r & -\mu & \cdots & 0 & 0 & 0 \\
\vdots & \vdots & \vdots & \vdots & \vdots & \vdots & \vdots \\
0 & 0 & 0 & \cdots & -\lambda & \lambda+\mu+r & -\mu \\
0 & 0 & 0 & \cdots & 0 & -\lambda & \mu+r
\end{array}\right|
$$

Determinant $P_{K-1}$ has the same form as determinant $P_{K}$, however, its dimension is $K-1$.

Determinant $P_{K}$ may be also written as:

$P_{K}=(\lambda+\mu+r) \cdot P_{K-1}-\lambda \cdot \mu \cdot P_{K-2}$.

Expression (8) presents second order homogeneous linear difference equation with constant coefficients [22], whose solution - determinant i.e. polynomial $P_{k}$ has the following form: (for $k=K$ )

$$
\begin{aligned}
& P_{k}=\frac{r+\mu-\lambda+\sqrt{s}}{2 \cdot \sqrt{s}} \cdot\left(\frac{(\lambda+\mu+r)+\sqrt{s}}{2}\right)^{k}+ \\
& +\frac{-(r+\mu-\lambda)+\sqrt{s}}{2 \cdot \sqrt{s}} \cdot\left(\frac{(\lambda+\mu+r)-\sqrt{s}}{2}\right)^{k},
\end{aligned}
$$

where $s=(\lambda+\mu+r)^{2}-4 \cdot \lambda \cdot \mu$.

By substituting the previous expression with expression (7) and by using algebra transformations expression $D_{K+1}$ may be written as:

$$
\begin{aligned}
& D_{K+1}=\left(\frac{1}{2}\right)^{K+1} \cdot r \cdot \frac{(2 \cdot \sqrt{\lambda \cdot \mu})^{K+1}}{2 \cdot \sqrt{\lambda \cdot \mu}} \cdot \\
& \frac{\left[X+\sqrt{X^{2}-1}\right]^{K+1}-\left[X-\sqrt{X^{2}-1}\right]^{K+1}}{\sqrt{X^{2}-1}},
\end{aligned}
$$

where $X=(\lambda+\mu+r) /(2 \cdot \sqrt{\lambda \cdot \mu})$.

Previous expression (10) which is in fact a polynomial of $K+1$ order, is also a characteristic polynomial of a $Q$ matrix multiplied with -1 , referred to as $Q(r)$ below.

Roots of the polynomial $Q(r)$ i.e. eigenvalues of the $Q$ matrix, given that the Chebyshev polynomial of the first order may be also written in trigonometric form, are: $r_{0}=0, r_{k}=2 \cdot \sqrt{\lambda \cdot \mu} \cdot \cos (k \cdot \psi)-\lambda-\mu ; k=1,2, \ldots, K$.

Analysis of determinant $D_{\bar{p}_{0}}$ structure shows that it may be calculated by using determinant $P_{k}$ (9), for different values of $k$, as follows:

$D_{\bar{p}_{0}}=\sum_{j=0}^{K} \pi_{j} \cdot \mu^{j} \cdot P_{K-j}$

Determinant $D_{\bar{p}_{0}}$, which is in fact a polynomial of Korder, will be further denoted as $P(r)$. Finally, the Laplace transform of system state probability $p_{0}(t)$ may be calculated as a ratio of two polynomials i.e. $\bar{p}_{0}=P(r) / Q(r)$.

Laplace transform inversion of system state probability $p_{0}(t)$ requires the expression $P(r) / Q(r)$ in the following form: [21]

$P(r) / Q(r)=A_{0} /\left(r-r_{0}\right)+\ldots+A_{K} /\left(r-r_{K}\right)$,

where $r_{k},(k=0,1, \ldots, K)$ are roots of the polynomial $Q(r)$ i.e. eigenvalues of the $Q$ matrix, defined with expression (11).

All roots of polynomial $Q(r)$ are real and different. Therefore coefficients $A_{k}(k=0,1, \ldots, K)$ may be calculated as:

$A_{k}=P\left(r_{k}\right) / Q^{\prime}\left(r_{k}\right)$,

where $Q^{\prime}\left(r_{k}\right)$ is the value of the first derivation of polynomial $Q(r)$ per $r$, for root $r_{k}$ of polynomial $Q(r)$, while $P\left(r_{k}\right)$ is a value of polynomial $P(r)$ for root $r_{k}$ of polynomial $Q(r)$.

Finally, the inverse Laplace transform of $\bar{p}_{0}$ is:

$$
\begin{aligned}
& p_{0}(t)=\mathscr{L}^{-1}\left\{\bar{p}_{0}\right\}=\mathscr{L}^{-1}\left\{\frac{P(r)}{Q(r)}\right\}= \\
& =\sum_{k=0}^{K} \frac{P\left(r_{k}\right)}{Q^{\prime}\left(r_{k}\right)} \cdot \mathscr{L}^{-1}\left\{\frac{1}{r-r_{k}}\right\}=\sum_{k=0}^{K} \frac{P\left(r_{k}\right)}{Q^{\prime}\left(r_{k}\right)} \cdot \mathrm{e}^{r_{k} \cdot t} .
\end{aligned}
$$

On the other hand, expression (5) for time dependent system state probabilities of the $M / M / 1 / K$ servicing system, for $i=0$ and after summation, is of the following form:

$$
p_{0}(t)=\sum_{k=0}^{K} C_{k} \cdot e^{r_{k} \cdot t}
$$

Comparison of expressions (13) and (14) shows that integration constants $C_{k}(k=0,1, \ldots, K)$ may be calculated as:

$C_{k}=P\left(r_{k}\right) / Q^{\prime}\left(r_{k}\right)$.

The reason why only system state probability $p_{0}(t)$ is interesting for determination of integration constants lies in the above expression. 
According to the roots of the polynomial $Q(r)$ i.e. eigenvalues of the $Q$ matrix, integration constant $C_{0}$ needs to be calculated separately from integration constants $C_{k}$ $(k=1,2, \ldots, K)$. Integration constant $C_{0}$ is obtained when root $r_{0}=0$ of polynomial $Q(r)$ is substituted in expression (15). Expression for integration constant $C_{0}$ has the following form:

$C_{0}=(1-\rho) /\left(1-\rho^{K+1}\right)$.

Integration constant $C_{k}$ is obtained when root $r_{k}=2 \cdot \sqrt{\lambda \cdot \mu} \cdot \cos (k \cdot \psi)-\lambda-\mu$ of polynomial $Q(r)$ is substituted in expression (15). Expression for integration constants $C_{k}(k=1,2, \ldots, K)$ has the following form:

$$
\begin{aligned}
& C_{k}=-\frac{2}{(K+1) \cdot r_{k}} \cdot \sum_{j=0}^{K} \pi_{j} \cdot \mu^{j} \cdot(\sqrt{\lambda \cdot \mu})^{1-j} . \\
& \cdot\{\sqrt{\rho} \cdot \sin [(j+1) \cdot k \cdot \psi]-\sin (j \cdot k \cdot \psi)\} \cdot \sin (k \cdot \psi) .
\end{aligned}
$$

Analytical expression for time dependent system state probabilities may be obtained by solving the differential equation system (3) only based on the Laplace transform. In this case, explicit analytical expressions for integration constants cannot be derived.

\section{Duration of non-stationary operating regime caused by initial conditions of warehouse servicing system}

Duration of the warehouse servicing system nonstationary operating regime, caused by initial conditions (number of pallets inside the goods acceptance area at the start of an operating day) will be determined as a moment of time when all relative errors $\left(\delta_{i}\right)$ between time dependent system state probabilities and appropriate limiting system state probabilities become lower than $1 \%$ i.e.: [23]

$\delta_{i}=\frac{\left|p_{i}(t)-p_{i}\right|}{p_{i}} \cdot 100 \leq 1 \%, \forall i \in(0,1, \ldots, K)$

where: $p_{i}(t)-i^{\text {th }}$ time dependent system state probability (5), and

$$
p_{i}=\rho^{i} \cdot(1-\rho) /\left(1-\rho^{K+1}\right), i=0,1, \ldots, K,
$$

are limiting system state probabilities. [24]

By substituting expressions for: time dependent system state probabilities (5), integration constants (16) and (17) and limiting system state probabilities (19) in expression (18) the following is obtained:

$$
\begin{aligned}
& \mid(\sqrt{\rho})^{i-1} \cdot \sum_{k=1}^{K}-\frac{2}{(K+1) \cdot r_{k}} \cdot \sum_{j=0}^{K} \pi_{j} \cdot \mu^{j} \cdot(\sqrt{\lambda \cdot \mu})^{1-j} . \\
& \cdot\{\sqrt{\rho} \cdot \sin [(j+1) \cdot k \cdot \psi]-\sin (j \cdot k \cdot \psi)\} . \\
& \cdot\{\sqrt{\rho} \cdot \sin [(i+1) \cdot k \cdot \psi]-\sin (i \cdot k \cdot \psi)\} \cdot e^{r_{k} \cdot t_{i}} \mid \leq
\end{aligned}
$$

$$
\leq \frac{1}{100} \cdot \frac{\rho^{i} \cdot(1-\rho)}{1-\rho^{K+1}}, \forall i=0,1, \ldots, K
$$

Based on the criteria defined by expression (18), duration of non-stationary operating regime of warehouse servicing system $t_{\text {stat }}$, represents the solution of transcendent inequalities (20) per variable $t_{i}$, for $\forall i=0,1, \ldots, K$, which has the maximum value:

$t_{\text {stat }}=\max \left\{t_{0}, t_{1}, \ldots, t_{K}\right\}$.

Duration of the warehouse servicing system nonstationary operating regimes for initial conditions defined by expression (2) (-+- N-S.R. 1) and initial conditions when the system is empty i.e. $\pi_{0}=1$ and $\pi_{i}=0$ for $i=1,2, \ldots$, 20 (-*- N-S.R. 2), obtained by solving transcendent inequalities (20), are shown in Fig. 3 depending on the warehouse servicing system utilisation factor $\rho$.

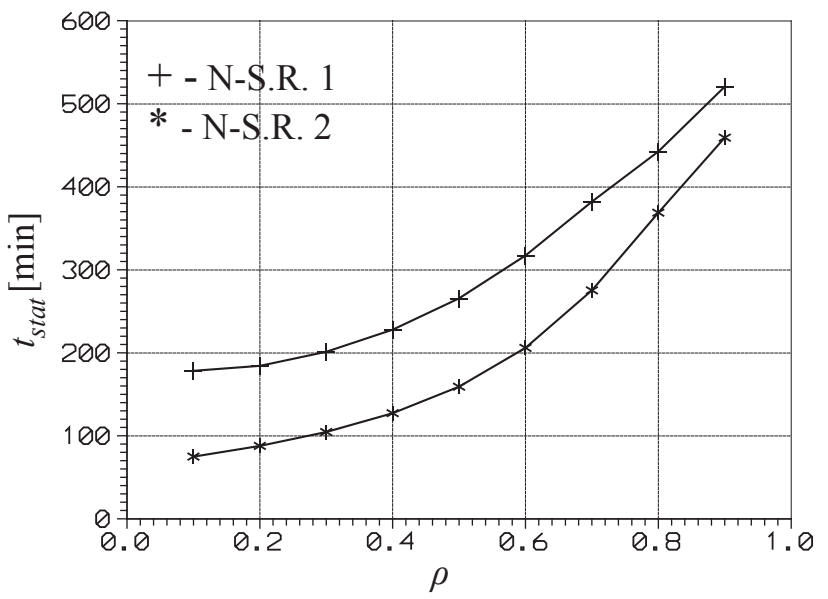

Figure 3 Duration of non-stationary operating regimes

For calculation purposes, the utilisation factor $\rho$ was gradually increased only by the change of mean arrival rate $\lambda$ while the mean servicing rate $\mu$ stayed the same (due to technical characteristics of the $\mathrm{S} / \mathrm{R}$ machine and the aisle changing device).

Fig. 3 shows that duration of non-stationary operating regimes of warehouse servicing system are increasing, in both analysed cases, with the utilisation factor $\rho$ increase. Durations of non-stationary operating regimes, when initial conditions are defined by expression (2), are higher than the ones obtained when the system is empty initially for all utilisation factor $\rho$ values. As the utilisation factor $\rho$ increases relative difference between durations of nonstationary regimes is decreasing from approximately $100 \%$ for $\rho=0,1$ to approximately $15 \%$ for $\rho=0,9$.

\section{Technological function parameters of warehouse servicing system in non-stationary operating regime}

Warehouse servicing system TFPs, as a function of $\rho$, analysed for both non-stationary regimes: when the system is empty (-*-, N-S.R. 2) and when initial conditions (number of pallets) are defined by expression (2) (-+-, N-S.R. 1) as well as for the stationary operating regime (---, S.R.) are: $N_{w s}$ - average number of units (pallets) in a servicing system (Fig. 4) and $t_{w s}$ - average time a unit (pallet) spends in a servicing system i.e. until 
it is stored in the rack (Fig. 5). Other TFPs: $P_{e q}$ - queue existence probability, $N_{w}$ - average number of units (pallets) in a queue - goods acceptance area and $t_{w}$ average time a unit (pallet) spends in a queue - goods acceptance area may be calculated in a similar way as the first two. Due to the paper length limitations their calculation was omitted.

Averaged values of warehouse servicing system state probabilities in a non-stationary operating regime $\hat{p}_{i}$ $(i=0,1, \ldots, K)$, used to calculate TFPs within the time interval $\left[0 \div t_{\text {stat }}\right]$, may be obtained as:

$$
\hat{p}_{i}=\frac{1}{t_{\text {stat }}} \cdot \int_{0}^{t_{\text {stat }}} p_{i}(t) \cdot d t \quad i=0,1, \ldots, K
$$

By substituting expressions (5), (16) and (17) in the above expression and by integrating it into the given limits, the final expression for $\hat{p}_{i}$ is obtained:

$$
\begin{aligned}
& \hat{p}_{i}=p_{i}+\frac{(\sqrt{\rho})^{j-1}}{t_{\text {stat }}} \cdot \sum_{k=1}^{K}-\frac{2}{(K+1) \cdot r_{k}^{2}} . \\
& \cdot \sum_{j=0}^{K} \pi_{j} \cdot \mu^{j} \cdot(\sqrt{\lambda \cdot \mu})^{1-j} . \\
& \cdot\{\sqrt{\rho} \cdot \sin [(j+1) \cdot k \cdot \psi]-\sin (j \cdot k \cdot \psi)\} . \\
& \cdot\{\sqrt{\rho} \cdot \sin [(i+1) \cdot k \cdot \psi]-\sin (i \cdot k \cdot \psi)\} . \\
& \cdot\left\{e^{\left.r_{k} \cdot t_{\text {stat }}-1\right\}, i=0,1, \ldots, K .}\right.
\end{aligned}
$$

Eq. (22) is an averaged value of the $i^{\text {th }}$ state probability of warehouse servicing system under a nonstationary operating regime (interval $\left[0 \div t_{\text {stat }}\right]$ ) for arbitrary initial conditions $\pi_{i}$.

The TFP calculation method, in non-stationary and stationary operating regimes, is shown in Tab. 1.

Table 1 Warehouse servicing system TFPs

\begin{tabular}{|c|c|c|}
\hline TFP & $\begin{array}{c}\text { Stationary } \\
\text { operating regime }\end{array}$ & $\begin{array}{c}\text { Non-stationary operating } \\
\text { regime }\end{array}$ \\
\hline$N_{w s}$ & $\sum_{i=0}^{K} i \cdot p_{i}$ & $\sum_{i=0}^{K} i \cdot \hat{p}_{i}$ \\
\hline$t_{w s}$ & $N_{w s} / \lambda_{\text {eff }}$ & $\frac{1}{t_{\text {stat }}} \cdot \int_{0}^{t_{\text {stat }}} \sum_{i=0}^{K} i \cdot \frac{p_{i}(t)}{\lambda_{\text {eff }}(t)} \cdot d t$ \\
\hline$\lambda_{\text {eff }}$ & $\mu \cdot\left(1-p_{0}\right)$ & $\mu \cdot\left[1-p_{0}(t)\right]$ \\
\hline$\lambda_{\text {eff }}$ average arrival rate. [23]
\end{tabular}

The change of the analysed warehouse servicing system TFPs is the same, meaning that the increase of $\rho$ implies the increase of TFP values.

Warehouse servicing system TFP values are worst in the case of a non-stationary operating regime for initial condition defined by expression (2) (-+-, N-S.R. 1). They are the best in the case of a non-stationary operating regime when the system is empty at the start of operation (-*-, N-S.R. 2), while the TFP values in a stationary operating regime (---, S.R.) are between the two obtained non-stationary values, closer to the values of a nonstationary operating regime when the system is empty.

Relationship between the warehouse servicing system TFPs, in a stationary operating regime and in the case of a non-stationary operating regime when the system is empty at the start of operation, indicates better values of the non-stationary operating regime. This happens when there are no pallets to be served leading to a temporary illusion that the $\mathrm{S} / \mathrm{R}$ machine capacity is unused. This lasts until the end of the non-stationary regime $\left[0 \div t_{\text {stat }}\right]$ i.e. until the arrival flow is balanced with servicing.

Relationship between the warehouse servicing system TFPs, in a stationary operating regime and in the case of non-stationary operating regime when the initial conditions are defined by expression (2), indicates worse values of the non-stationary operating regime. This happens when there are pallets at the start of operation causing a temporary illusion that the $S / R$ machine capacity is overloaded. This also lasts until the end of the non-stationary regime $\left[0 \div t_{\text {stat }}\right]$ i.e. until the arrival flow is balanced with servicing, except that in this case it takes more time than in the previous one.

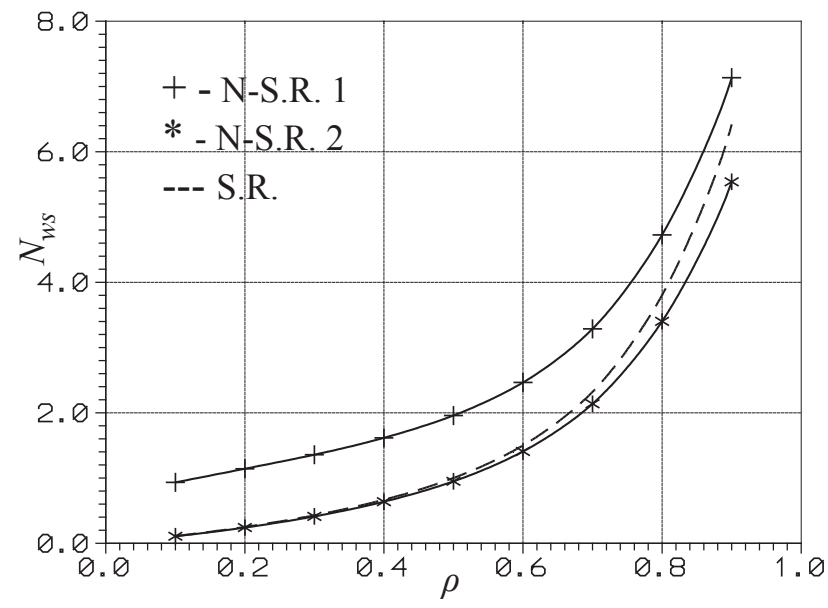

Figure 4 Average number of units (pallets) in a servicing system

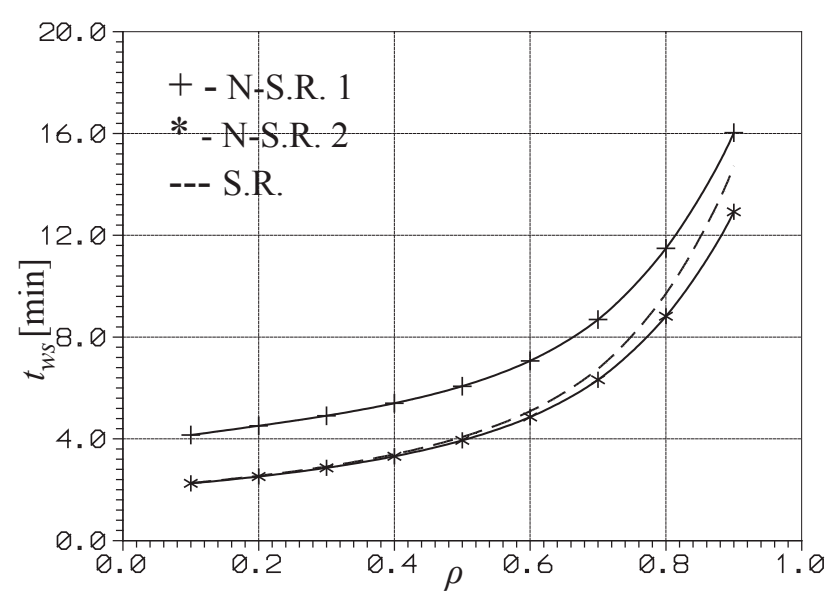

Figure 5 Average time a unit (pallet) spends in a servicing system

\section{Conclusion}

This paper examines warehouse servicing system operation in a non-stationary operating regime resulting from the existence of a certain number of pallets inside the goods acceptance area at the start of the operating day. 
Pallets inside the goods acceptance area result from different operating times (shifts) of production and warehouse systems.

The paper shows that operation i.e. servicing within the analysed warehouse may be modelled, with a single server servicing system including a finite waiting room i.e. $M / M / 1 / K$.

In order to identify the impact of the variable pallet number, inside the goods acceptance area, at the start of an operating day, authors recorded the number of pallets and obtained adequate theoretical probability distribution. The obtained Poisson distribution was used as an initial state probability distribution to calculate time dependent system state probabilities and TFPs of the warehouse servicing system under a non-stationary operating regime.

This has provided an explicit analytical expression for integration constants, identified following the general finite discrete probability distribution of the $M / M / 1 / K$ servicing system.

Integration constants are derived by using the Laplace transforms based on the specific properties of analytical expression for time dependent probability $p_{0}(t)$ of the $M / M / 1 / K$ servicing system. The obtained integration constants expression takes into consideration the initial system state impacts (through general finite discrete probability distribution) on the change of system state probabilities in time on a more general level than the known expressions described in literature.

Following the conducted analysis, it may be ascertained that a non-stationary operating regime influences warehouse servicing system TFPs.

Principally, the non-stationary operating regime caused by the existence of pallets inside the goods acceptance area lasts, depending on the utilisation factor, from three to eight hours. Such non-stationary regime, with the same utilisation factor, lasts longer than the nonstationary regime in cases when the goods acceptance area is empty. (Fig. 3)

Furthermore, when there are pallets inside the goods acceptance area at the start of an operating day, during the non-stationary operating regime, warehouse servicing system TFPs are worse than in the stationary operating regime. This practically means that the newly arrived pallets from the production line will spend more time inside the warehouse servicing system, while the number of pallets inside the goods acceptance area (queued units) in the non-stationary operating regime will be bigger than under the stationary operating regime. This adversely affects pallet distribution from the warehouse system requiring a larger acceptance area able to accept arriving pallets from the production line. It should be noted that TFP values are slightly better in a non-stationary regime when the goods acceptance area is empty than in the stationary operating regime. Both conclusions are applicable for interval $\left[0 \div t_{\text {stat }}\right]$ (Fig. 4 and Fig. 5).

When operation of a warehouse servicing system is observed within a longer time period, it may be concluded that a non-stationary operating regime when there are pallets inside the goods acceptance area reduces its capacity.

This has to be taken into consideration throughout the servicing system design where servicing devices operation is based on operating cycles with unbalanced operation of system parts in time.

\section{References}

[1] Song, J. S.; Zipkin, P. Inventory control in a fluctuating demand environment. // Operations Research. 41, 2(1993), pp. 351-370. DOI: 10.1287/opre.41.2.351

[2] Gullu, R. Base stock policies for production/inventory problems with uncertain capacity levels. // European Journal of Operation Research. 105, 1(1998), pp. 43-51. DOI: 10.1016/S0377-2217(97)00037-4

[3] Scheller-Wolf, A.; Tayur, S. A Markovian dual-source production-inventory model with order bands.Carnegie Mellon University, Pittsburgh, 1998.

[4] Erdem, A. S.; Ozekici, S. Inventory models with random yield in a random environment. // International Journal of Production Economics. 78, 3(2002), pp. 239-253. DOI: 10.1016/S0925-5273(01)00165-7

[5] Chen, F.; Yu, B. Quantifying the value of lead-time information in a single-location inventory system. // Manufacturing \& Service Operations Management. 7, 2(2005), pp. 144-151. DOI: 10.1287/msom.1040.0060

[6] Strijbosch, L. W.; Syntetos, A. A.; Boylan, J. E.; Janssen, E. On the interaction between forecasting and stock control: The case of non-stationary demand. // International Journal of Production Economics. 133, 1(2011), pp. 470-480. DOI: 10.1016/j.jpe.2009.10.032

[7] Iida, T. A non-stationary periodic review productioninventory model with uncertain production capacity and uncertain demand. // European Journal of Operational Research. 140, 3(2002), pp. 670-683. DOI: 10.1016/S03772217(01)00218-1

[8] Xu, N. Optimal policy for a dynamic, non-stationary, stochastic inventory problem with capacity commitment. // European Journal of Operational Research.199, 2(2009), pp. 400-408. DOI:10.1016/j.ejor.2008.11.032

[9] Treharne, J. T.; Sox, C. R. Adaptive inventory control for nonstationary demand and partial information. // Management Science. 48, 5(2002), pp. 607-624. DOI: 10.1287/mnsc.48.5.607.7807

[10] Takacs, L. Introduction to the Theory of Queues. Oxford University Press, London, 1962.

[11] Morse, P. M. Queues, Inventories and Maintenance: The Analysis of Operational Systems with Variable Demand and Supply. John Wiley \& Sons Inc., New York, 1958.

[12] Sharma, O. P.; Gupta, U. C. Transient behaviour of an $\mathrm{M} / \mathrm{M} / 1 / \mathrm{N}$ queue. // Stochastic Processes and their Applications. 13, 3(1982), pp. 327-331. DOI: 10.1016/03044149(82)90019-9

[13] Tababia, A. M. K.; El-Baz, A. H. Exact Transient Solutions of Nonempty Markovian Queues. // Computers and Mathematics with applications. 52, 6-7(2006), pp. 985-996. DOI: 10.1016/j.camwa.2006.04.022

[14] Tababia, A. M. K. Transient Analysis of M/M/1/N Queue An Alternative Approach. // Tamkang Journal of Science and Engineering. 3, 4(2000), pp. 263-266.

[15] Petrovic, D.; Bugaric, U.; Petrovic, Z. Preliminary design with elements of feasibility study of reconstruction of highbay warehouse in Galenika ad (in Serbian). Study, Tecon sistem d.o.o., Belgrade, 2010.

[16] Zrnic, Dj.; Petrovic, D. Stochastic processes in transport (in Serbian). Faculty of Mechanical Engineering Belgrade, Belgrade, 1994.

[17] Gudehus, T. Warteschlangen und Wartezeiten in Warenverteil- und Lagersystemen. // Fördern und Heben. 23, 5(1973), pp. 210-208.

[18] Bugaric, U. Modelling of transportation systems nonstationary operating regimes by applying the queuing 
theory (in Serbian). PhD Thesis, Faculty of Mechanical Engineering Belgrade, Belgrade, 2002.

[19] Sage, A. P.; White, C. C. Optimum System Control.Prentice-Hall, Eaglewood, 1977.

[20] Tabachnik, B. G.; Fidell, L. S. Using Multivariate Statistics. Pearson Education Inc., Boston, 2007.

[21] Kleinrock, L. Queueing Systems, Volume I: Theory. John Wiley \& Sons, New York, 1975.

[22] Bender, C. M.; Orszag, S. A. Advanced Mathematical Methods for Scientists and Engineers. McGraw-Hill, New York, 1978.

[23] Bugaric, U.; Petrovic, D. Modelling of servicing systems (in Serbian). Faculty of Mechanical Engineering Belgrade, Belgrade, 2011.

\section{Authors' addresses}

Uglješa Bugarić, professor

University of Belgrade, Faculty of Mechanical Engineering,

Kraljice Marije 16, 11120 Belgrade 35, Serbia

E-mail: ubugaric@mas.bg.ac.rs

Milan Vugdelija, M.Sc. math.

Microsoft Development Center Serbia,

Španskih boraca 3/3, 11070 Belgrade, Serbia

E-Mail: mdcsinfo@microsoft.com

\section{Dušan Petrović, professor}

University of Belgrade, Faculty of Mechanical Engineering, Kraljice Marije 16, 11120 Belgrade 35, Serbia

E-mail: dpetrovic@mas.bg.ac.rs

\section{Dušan Glišić, M.Sc. eng.}

Cyberdine Systems,

Molerova 35A, 11000 Belgrade, Serbia

E-mail: dusan.glisic@gmail.com

\section{Zoran Petrović, Ph.D. eng.}

Tecon sistem d.o.o., Serbia,

Antifašističke borbe 21b, 11070 Belgrade, Serbia

E-mail: zoran.petrovic@tecon.rs 